\title{
LA PROTESTA MEDIÁTICA COMO ESPEJO DEL RESURGIMIENTO CIUDADANO EN LA TRANSICIÓN DEMOCRÁTICA ESPAÑOLA
}

\section{THE MEDIA PROTEST AS A MIRROR OF THE CIVIL REAPPEARANCE, IN THE DEMOCRATIC TRANSITION OF SPAIN}

\author{
Sandra Méndez Muros \\ Universidad de Sevilla \\ sanmenmur@us.es
}

\section{Resumen:}

El artículo comienza por una revisión exhaustiva de las investigaciones existentes sobre el rol de la sociedad civil en la transición democrática de España. Aportan visiones confrontadas entre la desmovilización y el resurgimiento de la sociedad civil como agente de presión en las decisiones políticas.

Asimismo, este trabajo aporta investigación inédita sobre el tema utilizando una metodología de análisis de contenido para cuantificar las distintas formas de protesta social reflejadas en la prensa de Sevilla, entre 1975 y 1977. El análisis diferencia entre obreros, estudiantes, vecinos, artistas y ciudadanos. También cuantifica el flujo de noticias y los formatos de protesta (huelga- manifestación o nivel alto; y discurso-asociación o nivel bajo).

Los resultados confirman el protagonismo de la sociedad civil en impulsar el cambio democrático en España, detallando la evolución de la protesta por sectores, flujos y formatos. $Y$ se discute el papel de los medios de comunicación en estos procesos de cambio social.

Palabras clave: protesta mediática, resurgimiento ciudadano, transición democrática española, análisis contenido prensa, sociedad civil, movilización social.

\begin{abstract}
:
This paper begins with an exhaustive review of existing investigations on the role of the civil society in the democratic transition of Spain. They contribute visions confronted between demobilization and the reappearance of civil society as an agent of pressure in political decisions.
\end{abstract}

Additionally, this work presents information from unpublished investigations on this topic using a content analysis methodology to quantify the different forms of social protest reflected in the press of Seville between 1975 and 1977. The analysis identifies differences among workers, students, neighbors, artists and citizens. Also, it quantifies the flow of news and the formats of protest (strike - demonstration or high level; and speech - association or low level).

The results confirm the importance of civil society in stimulating democratic change in Spain, detailing the evolution of protest by sectors, flows and formats. And, the role of mass media in these processes of social change is discussed.

Key words: media protest, citizen reappearance, democratic transition of Spain, press content analysis, civil society, social mobilization. 


\section{Resurgimiento ciudadano versus desmovilización social}

Factores como el crecimiento económico y la modernización, la naturaleza política del franquismo, el aumento de la educación, el desarrollo de los medios de comunicación, el contexto internacional y la presión de una Europa democratizada han sido considerados suficientes por historiadores y sociólogos para explicar el cambio democrático producido durante la transición española ${ }^{1}$, desatendiendo en parte la acción de los actores no políticos que intervinieron en ella. En el plano de los protagonismos, se señala que el cambio es posible por una extraña confluencia de pragmatismo político y madurez ciudadana, pero no existe consenso sobre el grado de responsabilidad de cada uno en el proceso.

En los estudios históricos y sociológicos sobre la transición se contemplan esencialmente dos visiones ${ }^{2}$. Frente al papel de la sociedad española aceptadora de las propuestas de la clase política en una denominada transición democrática "desde arriba" (García San Miguel, 1981: 89 y 103) ${ }^{3}$, en la que se reconoce a lo sumo la lucidez política del pueblo español, se halla la teoría sobre el disenso social en la que se presenta a la sociedad civil como "un nuevo agente sociopolítico y económico en el que se sintetiza la capacidad de transformación que se puede emprender desde abajo" (Kaldor, 2005: 20-29).

Más allá de entender el "simplismo maniqueo" (Attili Card Amone, 2004: 146) de que los ciudadanos son el agente socializador de la democracia (los buenos) frente a la institución política gubernamental y/o partidista (los malos), hallamos que el debate perdura hasta nuestros días sobre dos ejes que explican el éxito de la transición: la desmovilización o el resurgimiento de la sociedad civil. Los basamentos de ambas posturas defendidas por sociólogos e historiadores son la existencia o ausencia de una cultura democrática entre los españoles y la influencia de las protestas sociales sobre las medidas tomadas por los políticos.

La ausencia de una cultura democrática entre los españoles explica las posiciones desmovilizadoras de los primeros años de la transición. El sociólogo López Pintor (1982: 53-80) concibe que los ciudadanos, a los que denomina "la mayoría indiferente" o "la mayoría ausente", advierten pasivos los principales catalizadores del proceso democrático: la muerte de Franco y el papel del rey Juan Carlos. El desinterés directo en la política, que hace que la población no esté dispuesta a verse en situaciones arriesgadas; la escasa porción de puntos de vista radicales y conservadores y la indefinición de ideas políticas, basada en la desinformación sistemática y el fácil recurso a la reacción autoritaria y defensiva son las principales razones argüidas (López Pintor y Buceta, 1975: 106). Desde la perspectiva histórica, autores como Palacio Atard (1989: 48-49) niegan que la movilización ciudadana tenga una fuerza destacable frente al rey y los políticos reformistas, pues no "ocasionaron grandes quebraderos de cabeza a los gobernantes".

Un sondeo realizado a mitad de los años ochenta entre los españoles sobre los orígenes de la transición revela, no obstante, que un 55\% de los entrevistados sostiene que la transición no habría tenido lugar sin la presión popular (Pérez Ledesma, 2006:

1 Véanse las obras de Juan J. Linz y Alfred Stepan (1996), Josep M. Colomer (1998), Carlos H. Waisman y Raanan Rein (2011), Diego Muro y Gregorio Alonso (2011).

2 Algunos autores como Weingast (2000) prefieren hablar de pacto entre los distintos actores sociales de acuerdo a incentivos.

3 La tesis de Christopher Hill (2005) concibe que son personas políticas claves (el rey, Suárez, Fernández Miranda) las que hacen posible la transición. 
126). La noción de creciente politización de la vida española es compartida en los mismos años por historiadores que se apoyan en la existencia de una cultura democrática, mediante la cual el peso de algunos sectores formados políticamente es vital, puesto que el peso de los obreros, estudiantes y la oposición fuerzan "a considerar el cambio democrático como la alternativa más factible” (Preston, 1986: 96).

Durante la última década del siglo $\mathrm{XX}$, la idea regeneradora convive con la de la desmovilización. Mientras que Linz (1992: 435-436) mantiene la concepción de que no existe una profunda crisis en la dictadura a la muerte de Franco que, incluso, goza de cierta estabilidad y, en cualquier caso, son las acciones de los gobernantes y no las condiciones estructurales e históricas las que determinan el futuro de una naciente democracia, algunas tesis sociológicas defienden el papel activo de la ciudadanía durante el proceso de transición, sustentándose en la idea de que el desmoronamiento interno y la crisis del régimen no habrían llevado por sí solas a la democratización (Köhler, 1995: 80). Más contundente es la noción del resurgimiento de la sociedad civil que expone la obra de Pérez Díaz (1987), producido gracias a la "invención" de la nueva cultura política desarrollada desde los años cincuenta, consistente en reivindicar temas éticos, morales, sociales, económicos y culturales, hasta el momento de exclusiva competencia política, a través de formas no institucionales de actuación (la protesta, la manifestación, el boicot, etc.).

Como contrapartida, se desarrolla la creencia de que es precisamente la desmovilización ciudadana la que favorece el cambio democrático. Para el sociólogo Cayo Sastre (1997: 65), la sociedad española no se moviliza ni por la democracia ni por el mantenimiento del régimen y deja "exclusivamente en manos de los políticos la resolución del problema que se plantea España en el año 1975". Añade que la desmovilización es un elemento que favorece la estrategia de cambio diseñada por las élites políticas españolas: "el proceso de redemocratización español se sustenta en un pacto entre élites que gozaron de un amplio margen para la negociación, favorecido por la existencia de una sociedad civil políticamente desmovilizada" (Sastre García, 1997: 43). La prueba es que tras la muerte de Franco no pasa "nada", bien por comodidad (el orden como statu quo, el cambio como riesgo), bien por miedo a la vuelta a una guerra civil o a la represión, dado el control ejercido por la capa política heredera del franquismo (Dorado y Varela, 1989: 251-274). Algunos autores admiten como causa histórica la indiferencia política ante la incorporación ciudadana de acuerdo a la "consolidada debilidad de la asunción de comportamientos democráticos: débil afiliación, escaso asociacionismo, menor implicación” (Lemus López, 1998: 498).

Simultáneamente, son numerosos los historiadores que apoyan la existencia de una cultura política dirigida hacia la democracia y no hacia el autoritarismo "de esa consistente minoría que prefería liderazgos fuertes y que se apoyaba a la coalición vencedora de la guerra civil" (Juliá y Mainer, 2000: 36-37). Se difunde la idea de que esta cultura descansa en el desarrollo socioeconómico que rompe la contribución del analfabetismo a la docilidad política, provocando el acceso a la formación y libre expresión (Seco Serrano, 1991: 252); favorece la difusión del conocimiento sobre lo que ocurre en el entorno europeo y el deseo de libertad y promueve corrientes de oposición en los sectores más instruidos (obreros, universitarios, profesionales, etc.) (Aróstegui, 2000: 22).

Estudios históricos más recientes recogen que el desgaste de la dictadura por presiones obreras y estudiantiles politizadas, a las que se suman otras demandas de asociaciones de vecinos o colegios oficiales, hacen que la supervivencia de la dictadura sea puesta en entredicho a la altura de noviembre de 1975 (Carrillo-Linares, 
2006: 169) y que la verdadera habilidad de los reformistas del franquismo no es tanto pilotar los acontecimientos como interpretar las "señales procedentes desde abajo, desde una sociedad civil crecientemente movilizada y demandante de nuevas y mayores libertades políticas" (Martín García, 2010: 140-144).

\section{La expresión social de la protesta}

En democracia, la sociedad civil debe ser apreciada como el ámbito donde los poderes sociales se formen y entren en conflicto para institucionalizarse ${ }^{4}$ (Attili Card Amone, 2004: 145). López Cantos (2006) sostiene el concepto de democracia al amparo de una teoría del conflicto entre intereses grupales enfrentados. La acción colectiva ${ }^{5}$ es, por tanto, el principal indicador para el estudio de la sociedad civil y toma forma a través del conflicto que presupone la confrontación y la organización de un colectivo social. El conflicto se materializa en diversas formas de protesta y ésta en el principal instrumento de expresión de la ciudadanía. Desde este enfoque, las tesis que defienden la desmovilización o el resurgimiento ciudadano divergen en la influencia de la contestación social en la agenda política a lo largo del proceso democratizador, tanto en términos de deslegitimación del poder político instaurado y la incapacidad de sus gobernantes como en la presión de reformas democratizadoras.

Entre los motivos que explican la exigua influencia de la expresividad reprobatoria ciudadana y llevan a hablar de despolitización de la sociedad, se halla la represión que impide la formación de un gran movimiento social (Saz Campos, 2010: 78-79). El Tribunal de Orden Público (TOP) ${ }^{6}$ castiga los delitos que subvierten los principios básicos del Estado, que alteran el orden público o agitan la conciencia nacional. Las manifestaciones son vistas con sospecha y desconfianza, puesto que trastornan las relaciones armoniosas entre el Estado y la sociedad (Jaime-Jiménez y Reinares, 1998: 166-187).

Los argumentos a favor de la efectividad de la protesta giran en torno a su aparición al margen del régimen, su creciente duración a partir de 1976, la facilidad por crear incertidumbre en el régimen y el aumento de la crisis de legitimidad (Soto, 1998: $151)$, sin olvidar la imagen internacional de la conflictividad que recogen los informes diplomáticos (Martín García, 2010: 139) y su configuración como elemento de presión en las negociaciones que están llevando los partidos políticos (Tusell y Soto, 1996: 378), generando una tensión sociopolítica cada vez más aguda.

Esta presión se genera en diversos sectores sociales (obreros, estudiantes, nacionalistas, etc.) (Conversi, 2002), pero es la lucha obrera, por cuestiones cuantitativas y cualitativas, la que contribuye al desgaste y la falta de credibilidad del régimen con la consecuente fragmentación de las familias políticas que integran el franquismo (Caro Cancela, 2000: 346). Es palpable la politización del movimiento obrero (Molinero e Ysás, 1992: 273), que en principio actúa por reivindicaciones laborales en un marco

4 Son las instituciones democráticas las que canalizan las discrepancias dentro de los mecanismos institucionales establecidos por la Constitución (Buil-Merce, 2000).

5 El sociólogo Rod Aya (1995: 107) matiza estos conceptos: "cualquier acción que la gente emprende para alcanzar metas comunes es acción colectiva. Cualquier acción colectiva que se emprende en contra de otra gente es confrontación. Y cualquier acción colectiva de confrontación que se emprende para remediar injusticias es protesta".

6 Órgano creado el 2 de diciembre de 1963 con la misión de juzgar las conductas consideradas por entonces como delitos políticos, principalmente, los delitos contra la seguridad interior del Estado. 
legal que prohíbe dos instrumentos básicos de la acción reivindicativa para defender sus intereses: la huelga y la libre asociación.

\section{La representación social en la realidad mediática}

El flujo comunicativo de la sociedad civil es necesario para que el sistema político adquiera legitimidad, teniendo en cuenta que la opinión pública está dominada por los medios de comunicación de masas (Habermas, 1998: 432). La idea del círculo hermenéutico o "dinámica circular de ida y vuelta" como sustituto del proceso de decisiones en una sola dirección está en la base de la formación democrática de la voluntad común y de la opinión pública que legitima las decisiones colectivas (De Zan, 2006).

Si bien es verdad que la política comunicativa durante el franquismo sumerge a la sociedad española en la pasividad y los despoja de alicientes para la movilización política, el progresivo relajamiento de la censura a raíz de la promulgación de la Ley de Prensa e Imprenta de 1966 provoca una actitud periodísticamente más activa. Desde los últimos años del régimen, los medios muestran, por un lado, las acciones de los actores sociales en un proceso de transformaciones y la ruptura de la imagen de un país sin problemas de orden público (Barrera, 1995: 19) y, por otro, se manifiestan como un agente mediador del proceso, poniendo en relación las demandas del ambiente social y las corrientes de decisiones del sistema político (Gomis, 1987: 308-310). Es en este proceso de mediación de la prensa donde se desarrolla la protesta mediática, entendida como la expresión del conflicto en el que está inmersa la sociedad civil y como acontecimiento noticiable que se crea en la calle, pero que, por su dimensión y efectividad, se reconfigura en los medios de comunicación. Desde esta óptica, la contestación ciudadana en la escena pública no sólo está conformada por la realidad de la calle, sino también por lo que de ella aparece en la realidad mediática.

Esta realidad mediática, concebida como una construcción humana y no como un espejo-reflejo de la realidad (Tuchman, 1972; Van Dijk, 2005) o como una reproducción de la realidad, como se acostumbra a interpretar desde los propios medios de comunicación (Aparici, 2010: 14-15), no impide que el lector pueda verse reflejado en lo que en ella acontece a través del concepto de 'otredad' como como el conjunto de creencias que nos identifica o nos separa de los otros (Rodrigo Alsina y Medina Bravo, 2009: 29-30). En el proceso de socialización, la prensa actúa insertando al ciudadano en la sociedad mediante el reconocimiento en el otro, poniendo en común códigos, actitudes, valores, ideas dominantes, visiones, expectativas, objetivos, etc. para facilitar la convivencia y la integración social. Como observa Ferrés I Prats (2003: 56-59), la personalidad es construida a partir de una serie sucesiva de identificaciones a partir de modelos que se viven como gratificantes y que permiten construir el imaginario colectivo en el que los medios cumplen la función doble de ser reflejo y moduladores.

\section{Metodología}

Como hemos observado, el papel de la sociedad civil durante la transición democrática ha sido ampliamente tratado por historiadores y sociólogos, no así por historiadores de la comunicación. La función política más relevante atribuida a los medios de comunicación en relación a los ciudadanos durante el proceso democrático ha sido 
la de resocializar a la ciudadanía para que reconociera la legitimidad del régimen democrático y asumiera las nuevas formas de comportamiento, en la creencia de que la prensa a grandes rasgos contribuye "mucho más que la mayor parte de los grupos políticos a la difusión del ideario democrático" (Tusell, 1989: 203).

En nuestra investigación, entendemos que los posicionamientos sobre el resurgimiento o la desmovilización de la sociedad civil deben contemplar que la protesta social encuentra en los medios de comunicación una plataforma que amplía la escena pública de la calle y que la prensa sevillana de libre empresa y distinto signo ideológico hace una apuesta clara por el cambio democrático con la inclusión del conflicto social como valor/noticia. De acuerdo a ello, buscamos exponer que existe un resurgimiento ciudadano mediático a través del estudio del repertorio de la protesta y la comprobación de que la sociedad civil $^{7}$ ejerce una influencia y/o presión en las decisiones de la clase política dirigente. También pretendemos demostrar que el papel resocializador de la prensa es más amplio en la medida en la que configura la actitud de la sociedad española en el proceso democrático.

Hemos llevado a cabo un análisis micro social tomando como muestra a los ciudadanos de Sevilla por varias razones: 1) es una de las capitales españolas más activas en la demanda de libertades democráticas y la ciudad más politizada del sur de España por las acciones de oposición política y de lucha obrera (Vilar, 1976: 323); 2) la embajada británica la considera la ciudad española que avista el crecimiento industrial más rápido en los últimos años a la vez que es "presa de la endémica conflictividad laboral" (Martín García, 2010: 138-139) y 3) en ella los sindicatos con mayor capacidad de movilización consiguen llevar a cabo grandes manifestaciones entre 1976 y 1977. Además, su elección resulta útil atendiendo a la idea de González de Molina y Gómez Oliver (2000: 468) sobre que el proceso político de la transición en Andalucía no difiere en absoluto de lo acontecido en el resto del estado español.

Del espectro periodístico del momento hemos seleccionado dos medios ${ }^{8}$ pertenecientes al sector privado de la prensa local, Abc de Sevilla (1929) y El Correo de Andalucía (1899), que, al contrario de la prensa pública y oficial, practica la crítica y reclama más altos niveles de libertad y desarrollo político (Sinova, 1989: 262), pese a que sus antecedentes durante el tardofranquismo nos llevan a discurrir dos modos distintos de entender la 'desobediencia civil'. El Correo de Andalucía acoge temas y actores de conflictos pertenecientes a los sectores sociales que no son oídos en otros medios de comunicación de la ciudad (universitarios, obreros, sacerdotes, exiliados y presos políticos o sindicalistas), mientras que $A b c$ de Sevilla es un periódico que considera que los elementos sociales deben estar al lado de la ley sin perturbar el orden público.

Tomando en consideración que la prensa supone un segundo nivel de expresión (el primero es la realidad, la calle) con el resultante proceso de selección y jerarquización mediante criterios informativos, hemos realizado el análisis de contenido de una muestra total de 983 textos (Abc, 363; El Correo de Andalucía, 620) que versan

7 Para De Villiers (1999), aunque estas medidas son implementadas unilateralmente por Adolfo Suárez, responden a las peticiones de la oposición, por lo tanto, estas demandas desde abajo mantienen el proceso de transformación interna del régimen autoritario en el futuro.

8 Entre 1976 y 1977 la difusión de ambos periódicos es de más de 85.500 lectores: Abc de Sevilla (54.259 lectores) y El Correo de Andalucía (31.249 lectores). 
sobre la contestación ciudadana ${ }^{9}$ con un margen de error del $5 \%$ en la búsqueda y selección del material. El período de investigación comprende diez bimestres entre noviembre de 1975 (muerte de Franco) y junio de 1977 (primeras elecciones generales) en clara sintonía con las tres fases que señalan O'Donnell y Schmitter (1986: $46)^{10}$ a la hora de describir el ciclo de protestas. También nos resulta útil seguir el trabajo de Schuster (2005: 65) que, dentro de una amplia perspectiva metodológica sobre la acción colectiva, identifica dos ejes para el estudio empírico llevado a cabo: el acontecimiento y la acción.

En nuestro caso, nos centramos, por un lado, en la matriz identitaria de los protagonistas, para lo cual fraccionamos a la sociedad civil sevillana en cinco categorías o sectores sociales, cuyo fin no es estrictamente hacer política: obrero (conjunto de trabajadores que no son propietarios de los medios de producción), estudiantil (integrantes del ámbito formativo y académico de todos los niveles educativos), vecinal (comunidad de personas que viven en un mismo barrio), cultural/artístico (representantes del mundo de la cultura y del espectáculo) y ciudadano (habitantes españoles con derechos y deberes). Y, por otra parte, estudiamos el ciclo exclamatorio, esto es, el flujo noticioso y formatos del repertorio de acción colectiva o configuraciones estructurales. El flujo de la contestación es medido desde parámetros cuantitativos (porcentaje de textos) univariables (flujo por sectores y bimestres) y bivariables (evolución diacrónica y sincrónica del flujo por sectores sociales y bimestres).

Para comprender la protesta, algunos sociólogos históricos se basan en las reivindicaciones que la motivan. De esta forma, las manifestaciones pueden ser catalogadas como estudiantiles, gremiales, políticas y culturales. Otros hablan de características particulares de los denominados 'repertorios' de acción colectiva o conjuntos factibles de rutinas ensayadas y compartidas, esto es, cada grupo social cuenta con su propio repertorio cultural, el cual varía dependiendo del contexto ${ }^{11}$ (Auyero, 2002: 188),

En este último caso, encontramos las clasificaciones de Charles Tilly (1978) y de Sidney Tarrow (2004). Para el primero, existen esencialmente dos tipos de repertorios de acción. Uno más antiguo que contiene formas violentas, rígidas, locales y directas (motines religiosos, destrucción de maquinaria, quema de cosechas, etc.) y otro más actualizado que se compone de movilizaciones más pacíficas, flexibles, nacionales e indirectas (mítines, manifestaciones, huelgas, etc.), cuyos resultados son más efectivos en la llamada de atención y en la negociación. Tarrow, por su parte, distingue entre enfrentamientos violentos, alteración creativa del orden y manifestación pública convencional, que aglutina las expresiones más tradicionales y reconocidas de los movimientos organizados. Estas últimas permanecen normalizadas en el tiempo, sin

9 Las demandas de los sectores analizados, excepto el sector ciudadano, no son exclusivamente políticas (amnistía para los represaliados políticos y sindicales y libertades democráticas), sino que aparecen unidas a reivindicaciones estipuladas en el sector obrero (mejoras salariales, de las condiciones de trabajo, readmisiones de despedidos), estudiantil (escolarización total y gratuita, renovación de estructuras universitarias, sindicatos democráticos, readmisión de estudiantes y profesores, solidaridad con obreros, rechazo del control policial universitario), cultural/ artístico (libertad de pensamiento, expresión y cultura) y vecinal (viviendas, servicios públicos).

10 En forma de "U" invertida: una ascendente en la que el interés por lo político renace y cada vez más ciudadanos se suman a las protestas; la segunda fase en donde se alcanza la cima de la ola y la tercera fase, donde se inicia descenso que supone la desmovilización y la reducción del número de protestas.

11 La consolidación democrática se ve favorecida si los conflictos y las demandas sociales se manejan mediante procedimientos previsibles y aceptados ampliamente (Valenzuela, 1990). 
olvidar que los repertorios suelen evolucionar lentamente de acuerdo a las expectativas de los demás. Si aunamos ambos criterios, las características del conflicto condicionan el modo en que los repertorios funcionan, entablándose una estrecha relación entre el tipo de conflicto y el tipo de protesta. Por ejemplo, los obreros van mayoritariamente a la huelga o los estudiantes hacen manifestaciones.

Los formatos del repertorio de protesta han sido divididos en nuestro caso en: huelga, manifestación, discurso y asociación, junto a los principales términos sinónimos bajo los que aparecen publicados en la prensa de la época (véase cuadro 1), dispuestos en dos niveles de conflictividad: nivel 10 alto (manifestaciones y huelgas) y nivel 2 o bajo (discursos y asociaciones), de acuerdo a los problemas de orden público generados entre actores contestatarios y fuerzas de orden público, con la consecuente imagen violenta de los hechos. Estos formatos son estudiados desde el análisis cualitativo univariable (formatos por sectores, evolución diacrónica y sincrónica de formatos por bimestres y evolución de niveles de conflictividad) y bivariable (evolución diacrónica y sincrónica de formatos por sectores sociales y bimestres). Los resultados expuestos en tablas de contingencia son interpretados en el contexto histórico en el que se producen las políticas reformadoras para comprobar si existe una modulación mediática de la contestación social.

Cuadro 1. Tipología de formatos del repertorio de protesta de la sociedad civil en la prensa durante la transición democrática española

\begin{tabular}{|c|c|c|c|}
\hline Formato & Términos relacionados y sinónimos & Ámbito & Espacio \\
\hline Manifestación & $\begin{array}{l}\text { marcha, encierro, concentración, } \\
\text { sentada, campamento, cacerolada, } \\
\text { ocupación de edificios públicos, } \\
\text { bloqueo, motín, acto de desobediencia } \\
\text { civil, lucha, revuelta, desorden público, } \\
\text { disturbio, corte de tráfico }\end{array}$ & $\begin{array}{l}\text { obrero, } \\
\text { estudiantil, } \\
\text { ciudadano, } \\
\text { cultural/artistico, } \\
\text { vecinal }\end{array}$ & $\begin{array}{l}\text { la calle, } \\
\text { edificios } \\
\text { públicos, } \\
\text { lugares } \\
\text { públicos }\end{array}$ \\
\hline Huelga & $\begin{array}{l}\text { paro, boicot, cese, interrupción, } \\
\text { inactividad }\end{array}$ & $\begin{array}{l}\text { obrero, } \\
\text { estudiantil, } \\
\text { cultural/artistico }\end{array}$ & lugar de trabajo \\
\hline Discurso & $\begin{array}{l}\text { escrito, declaración, carta, canción, } \\
\text { conferencia, mitin, mesa redonda, } \\
\text { exposición, charla, coloquio, recital }\end{array}$ & $\begin{array}{l}\text { laboral, } \\
\text { estudiantil, } \\
\text { ciudadano, } \\
\text { vecinal, } \\
\text { cultural/artístico }\end{array}$ & $\begin{array}{l}\text { lugares y } \\
\text { estrados } \\
\text { públicos o } \\
\text { privados }\end{array}$ \\
\hline Asociación & $\begin{array}{l}\text { plataforma, organización, } \\
\text { confederación, consorcio, unión, } \\
\text { comunidad, agrupación, federación, } \\
\text { sociedad, club, círculo }\end{array}$ & $\begin{array}{l}\text { laboral, } \\
\text { estudiantil, } \\
\text { ciudadano, } \\
\text { vecinal, } \\
\text { cultural/artistico }\end{array}$ & $\begin{array}{l}\text { lugares } \\
\text { públicos y } \\
\text { privados }\end{array}$ \\
\hline
\end{tabular}

Fuente: Elaboración propia

\section{Análisis de la influencia de la protesta social mediática en las medidas políticas democratizadoras}

\subsection{De la prudencia a la contestación en la calle por la amnistía}

Tras la muerte de Franco y la subida al trono de Juan Carlos I en noviembre de 1975, la ciudadanía que se está desarrollando desde los últimos años del franquismo espera el cambio democrático. En el proceso de definición de este cambio, en la prensa se refleja una demanda social todavía minoritaria con una protesta de impacto calle- 
jero del $6,1 \%$ y un talante prudente que se debate en el empleo de formatos de nivel $1(53,33 \%)$ y de nivel $2(46,66 \%)$.

No todos los sectores se hacen eco de la misma forma de la aprobación del primer indulto del reinado, del que se benefician tres dirigentes sevillanos de Comisiones Obreras (CCOO) enjuiciados por el Proceso 1.001. El sector obrero, que protagoniza la acción reprobatoria del bimestre noviembre-diciembre de 1975 (53,33\%), es el que reacciona recurriendo en mayor proporción a formatos de nivel 1, especialmente manifestaciones (56,25\%), donde se suceden peticiones de amnistía y reivindicaciones laborales en medio de las negociaciones de convenios colectivos y los primeros intentos de unidad sindical.

Los discursos, además de ser los segundos formatos más aplicados por los obreros $(28,12 \%)$, se imponen en el sector estudiantil $(64,7 \%)$ por encima de las manifestaciones $(29,41 \%)$ para pedir la amnistía de profesores represaliados y mostrarse en contra de la prohibición de reuniones. Mientras los sectores vecinal y cultural/artístico no despiertan con fuerza aún, el sector ciudadano, cuya presencia periodística es del $13,33 \%$, se debate al $50 \%$ entre formatos de nivel 1 y de nivel 2 para demostrar su descontento por la continuidad del régimen franquista que supone el nombramiento de Carlos Arias Navarro como presidente del Gobierno y ante la insatisfacción que causa el indulto, demostrada en la jornada pro-amnistía del 12 de diciembre que organiza la Junta Democrática y la Plataforma de Convergencia Democrática.

En los meses de enero-febrero de 1976 se publica el mayor número y diversificación de textos que canalizan respuestas de descontento, pudiéndose hablar de la primera oleada contestataria de la transición, donde la cobertura periodística es del $26,34 \%$ (obsérvese la figura 1) y el nivel 1 de conflictividad asciende al 71,42\%. En general, todos los formatos registran sus datos máximos del período de análisis, siendo las huelgas $(38,99 \%)$ las que se imponen en el bimestre sobre el resto. El estallido es particularmente apreciable en los sectores obrero y estudiantil, que alcanzan los porcentajes más elevados de flujo informativo en el ciclo global estudiado (véase tabla 3) y ocupan más del $85 \%$ de las noticias sobre protesta, en su mayor parte dirigida a la petición de amnistía y libertades democráticas.

Figura 1. Evolución diacrónica de piezas informativas sobre protestas en la prensa de Sevilla

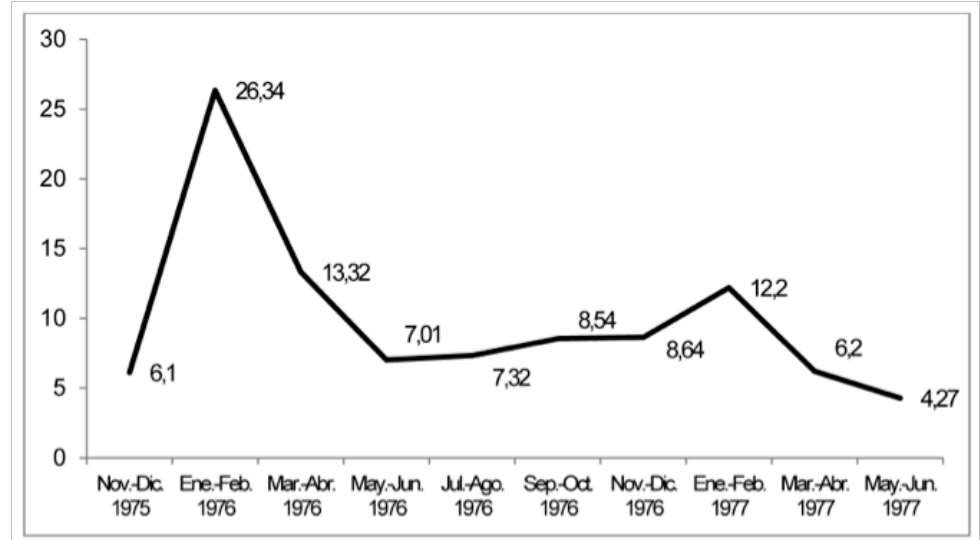

Fuente: Elaboración propia 
En el sector obrero abundan las manifestaciones (33,75\%), aunque en la lucha se impone las huelgas $(53,5 \%)$ en el campo del metal y la construcción, en un momento en el que los primeros contactos entre los sindicatos CCOO, UGT (Unión General de Trabajadores), USO (Unión Sindical Obrera) y CNT (Confederación Nacional del Trabajo) para formar una Coordinadora Sindical no ofrecen resultados. El ámbito estudiantil se vale esencialmente de las manifestaciones $(36,92 \%)$ en su búsqueda de la renovación de la estructura educativa y universitaria y como testimonio de solidaridad con los obreros. Es destacable que los valores logrados en este bimestre por las huelgas $(42,42 \%)$ y manifestaciones $(39,84 \%)$ obreras y por todos los formatos del sector estudiantil ostentan los valores supremos de toda la muestra temporal investigada.

La prohibición de conciertos y recitales es uno de los motivos que hace que el sector cultural/artístico alcance su mayor apunte en el transcurso completo considerado $(32,3 \%)$ en cuanto a flujo informativo, fundamentalmente a través de manifestaciones $(9,52 \%)$, dato excepcional cuando suele expresarse a través del diálogo. La exposición de la protesta del resto de sectores es mucho más limitada y se decanta por formatos dialécticos y, en menor medida, asociativos. Estos últimos aparecen por vez primera en el sector ciudadano $(11,11 \%)$, que opera sobre todo con los discursos $(55,55 \%)$ en unas circunstancias en las que el programa reformista de Arias Navarro no convence, la oposición política está dando sus primeros pasos para organizarse y se perpetúa un gobierno local no elegido por cauces democráticos.

Tabla 1. Evolución de los formatos de protesta en la prensa de Sevilla (1975-1977)

\begin{tabular}{|c|c|c|c|c|}
\hline \multicolumn{5}{|c|}{ Evolución diacrónica de los formatos de protesta (cada formato en todos los bimestres) } \\
\hline & $\begin{array}{c}\text { Manifestaciones } \\
\%\end{array}$ & $\begin{array}{c}\text { Huelgas } \\
\%\end{array}$ & $\begin{array}{c}\text { Discursos } \\
\%\end{array}$ & $\begin{array}{c}\text { Asociaciones } \\
\%\end{array}$ \\
\hline Nov.-Dic. 1975 & 8,85 & 1,83 & 8,51 & 1,13 \\
\hline Ene.-Feb. 1976 & 27,54 & 36,99 & 18,29 & 18,18 \\
\hline Mar.-Abr. 1976 & 14,09 & 20,51 & 8,20 & 6,81 \\
\hline May.-Jun. 1976 & 5,90 & 5,86 & 7,25 & 13,63 \\
\hline Jul.-Ago. 1976 & 9,50 & 3,66 & 8,83 & 5,68 \\
\hline Sep.-Oct. 1976 & 12,13 & 4,39 & 7,25 & 13,63 \\
\hline Nov.-Dic. 1976 & 7,21 & 10,62 & 8,51 & 7,95 \\
\hline Ene.-Feb. 1977 & 9,50 & 8,05 & 17,66 & 14,77 \\
\hline Mar.-Abr. 1977 & 4,26 & 2,93 & 9,46 & 11,36 \\
\hline May.-Jun. 1977 & 0,98 & 5,12 & 5,99 & 6,81 \\
\hline \multicolumn{5}{|c|}{ Evolución sincrónica de los formatos de protesta (todos los formatos en cada bimestre) } \\
\hline & $\begin{array}{c}\text { Manifestaciones } \\
\%\end{array}$ & $\begin{array}{c}\text { Huelgas } \\
\%\end{array}$ & $\begin{array}{c}\text { Discursos } \\
\%\end{array}$ & $\begin{array}{c}\text { Asociaciones } \\
\%\end{array}$ \\
\hline Nov.-Dic. 1975 & 45,00 & 8,33 & 45,00 & 1,66 \\
\hline Ene.-Feb. 1976 & 32,43 & 38,99 & 22,39 & 6,17 \\
\hline Mar.-Abr. 1976 & 32,82 & 42,74 & 19,84 & 4,58 \\
\hline May.-Jun. 1976 & 26,08 & 23,18 & 33,33 & 17,39 \\
\hline Jul.-Ago. 1976 & 40,27 & 13,88 & 38,88 & 6,94 \\
\hline Sep.-Oct. 1976 & 44,04 & 14,28 & 27,38 & 14,28 \\
\hline Nov.-Dic. 1976 & 25,88 & 34,11 & 31,76 & 8,23 \\
\hline Ene.-Feb. 1977 & 24,16 & 18,33 & 46,66 & 10,83 \\
\hline Mar.-Abr. 1977 & 21,31 & 13,11 & 49,18 & 16,39 \\
\hline May.-Jun. 1977 & 7,14 & 33,33 & 45,23 & 14,28 \\
\hline
\end{tabular}

Fuente: Elaboración propia 
Las jornadas de conflictividad se agudizan en los meses de marzo y abril, sin embargo, el porcentaje de desacuerdo en prensa se reduce a la mitad con respecto al bimestre anterior $(13,32 \%)$ a la vez que tiene lugar el distanciamiento más acusado entre formatos de nivel 1 y 2 con una preponderancia de los primeros en un $75,56 \%$; sustancialmente, las huelgas son las protagonistas con un $42,74 \%$ de cobertura informativa sobre el resto de formatos, como recoge la tabla 1. Esto es más relevante en el sector obrero sevillano, que encabeza la protesta $(48,85 \%)$, donde medio centenar de cargos sindicales convocan la jornada pro-amnistía a través de un documento público en el que rechazan abiertamente el carácter antiobrero y reaccionario de la violencia desatada contra los trabajadores en acción y llaman a las fuerzas democráticas legales e ilegales por la descongelación salarial y la amnistía. Los formatos de nivel 1 continúan logrando los apuntes más cruciales, esto es, manifestaciones $(23,43 \%)$ y, sobre todo, huelgas $(62,5 \%)$, mientras las direcciones centrales de CCOO y USO hacen público su respaldo a todos los cargos sindicales democráticos.

También en el sector estudiantil se incrementan las huelgas y manifestaciones, resultando un $80 \%$ de la contestación, y progresa el flujo informativo cinco puntos con respecto al bimestre anterior $(30,53 \%)$ en detrimento del sector obrero, ayudado por la duplicación del porcentaje de aparición mediática del sector ciudadano (13,74\%). Comienza entonces su escalada mediante las manifestaciones $(55,55 \%)$ como vehículo de inconformismo por encima de los discursos (44,44\%), revelando un carácter combativo que se mantiene hasta finales del verano. En estos momentos, el movimiento asociativo únicamente tiene fuerza en el sector vecinal, donde las asociaciones se desarrollan progresivamente y son administradas en la misma cantidad que las manifestaciones (40\%).

\subsection{Legalización del repertorio: diálogo ciudadano versus protesta obrera y estudiantil en la calle}

En los meses de mayo y junio de 1976, cuando la contestación disminuye nuevamente a la mitad $(7,01 \%)$ en relación al bimestre anterior y sólo adquiere un punto más desde el inicio de la transición, se promueve una ecuanimidad en la prensa con la disposición de formatos de nivel $1(49,26 \%)$ y nivel $2(50,72 \%)$. Se atenúan las huelgas y las manifestaciones y los discursos (33,33\%) se van imponiendo de forma paulatina, a la vez que se origina un avance considerable de las asociaciones $(17,39 \%)$.

Esto es especialmente evidente en el sector obrero, que hasta el final del período cultiva un flujo informativo no superior al $9 \%$, si bien en el bimestre representa el $52,1 \%$ de la protesta. Los moderados logros de la Ley 16/1976, de 8 de abril, de Relaciones Laborales y los objetivos del $1^{\circ}$ de Mayo (libertad sindical, amnistía, descongelación salarial, derecho de huelga, sindicato obrero y rechazo a la represión patronal) son reivindicados con formatos de protesta de nivel $2(52,77 \%)$ por encima de los de nivel $1(47,21 \%)$-las manifestaciones cosechan su segundo dato mínimo del intervalo de tiempo absoluto analizado (3,75\%)- y, aunque las huelgas $(33,33 \%)$, entre las que se encuentra la del 23 de junio que afecta a unos dieciséis mil obreros, se imponen al resto de formatos, representan la mitad del valor del bimestre anterior y las asociaciones experimentan $(25 \%)$ un llamativo auge, que asume la mayor proporción del total de espacio temporal examinado (18\%).

La acción estudiantil continúa en segunda posición respecto a otros sectores, pero se comprime periodísticamente al $21,73 \%$. Aunque las huelgas ocupan el $26,66 \%$, se confirma una tendencia dialéctica (53,33\%). Cabe pensar que la Ley $17 / 1976$, de 
29 de mayo, reguladora del derecho de reunión satisface de alguna manera a estos sectores y frena el impacto de la protesta en la calle. Pero, el descenso de los formatos de nivel 1 en la prensa, también coincide con el apoyo internacional a las políticas ejecutadas en España ${ }^{12}$ y el papel del rey en el extranjero ${ }^{13}$.

Tabla 2. Flujo informativo de protesta según sectores y bimestres en la prensa de Sevilla (1975-1977)

\begin{tabular}{|c|c|c|c|c|c|}
\hline \multicolumn{6}{|c|}{ Evolución diacrónica del flujo informativo (cada sector en todos los bimestres) } \\
\hline & $\begin{array}{c}\text { Sector } \\
\text { obrero } \\
\%\end{array}$ & $\begin{array}{c}\text { Sector } \\
\text { estudiantil } \\
\%\end{array}$ & $\begin{array}{c}\text { Sector } \\
\text { vecinal } \\
\%\end{array}$ & $\begin{array}{c}\text { Sector } \\
\text { cultural/artístico } \\
\%\end{array}$ & $\begin{array}{c}\text { Sector } \\
\text { ciudadano } \\
\%\end{array}$ \\
\hline Nov.-Dic. 1975 & 6,73 & 6,29 & 0,00 & 4,61 & 6,55 \\
\hline Ene.-Feb. 1976 & 33,05 & 24,07 & 13,72 & 32,30 & 7,37 \\
\hline Mar.-Abr. 1976 & 13,47 & 14,81 & 9,80 & 6,15 & 14,75 \\
\hline May.-Jun. 1976 & 7,57 & 5,55 & 5,88 & 3,07 & 10,65 \\
\hline Jul.-Ago. 1976 & 8,00 & 1,48 & 5,88 & 4,61 & 19,67 \\
\hline Sep.-Oct. 1976 & 6,31 & 12,59 & 15,68 & 0,00 & 9,83 \\
\hline Nov.-Dic. 1976 & 8,63 & 7,77 & 9,80 & 9,23 & 9,83 \\
\hline Ene.-Feb. 1977 & 5,26 & 20,37 & 19,6 & 30,76 & 8,19 \\
\hline Mar.-Abr. 1977 & 6,31 & 4,81 & 7,84 & 4,61 & 9,01 \\
\hline May.-Jun. 1977 & 4,63 & 2,22 & 11,76 & 4,61 & 4,09 \\
\hline \multicolumn{6}{|c|}{ Evolución sincrónica del flujo informativo (todos los sectores en cada bimestre) } \\
\hline & $\begin{array}{c}\text { Sector } \\
\text { obrero } \\
\%\end{array}$ & $\begin{array}{c}\text { Sector } \\
\text { estudiantil } \\
\% \\
\end{array}$ & $\begin{array}{c}\text { Sector } \\
\text { vecinal } \\
\%\end{array}$ & $\begin{array}{c}\text { Sector } \\
\text { cultural/artístico } \\
\%\end{array}$ & $\begin{array}{c}\text { Sector } \\
\text { ciudadano } \\
\% \\
\end{array}$ \\
\hline Nov.-Dic. 1975 & 53,33 & 28,33 & 0,00 & 5,00 & 13,33 \\
\hline Ene.-Feb. 1976 & 60,61 & 25,09 & 2,70 & 8,10 & 3,47 \\
\hline Mar.-Abr. 1976 & 48,85 & 30,53 & 3,81 & 3,05 & 13,74 \\
\hline May.-Jun. 1976 & 52,10 & 21,73 & 4,34 & 2,89 & 18,84 \\
\hline Jul.-Ago. 1976 & 52,77 & 5,55 & 4,16 & 4,16 & 33,33 \\
\hline Sep.-Oct. 1976 & 35,71 & 40,47 & 9,52 & 0,00 & 14,28 \\
\hline Nov.-Dic. 1976 & 48,23 & 24,70 & 5,88 & 7,05 & 14,11 \\
\hline Ene.-Feb. 1977 & 20,83 & 45,83 & 8,33 & 16,66 & 8,33 \\
\hline Mar.-Abr. 1977 & 49,18 & 21,31 & 6,55 & 4,91 & 18,03 \\
\hline May.-Jun. 1977 & 52,38 & 14,28 & 14,28 & 7,14 & 11,90 \\
\hline
\end{tabular}

Fuente: Elaboración propia

Las suspicacias se dirigen hacia el gobierno de Arias Navarro, que en estos meses acuerda enviar a las Cortes el Proyecto de Ley de Sucesión de la Corona, de la Reforma de la Ley Constitutiva de las Cortes y de la Ley Orgánica del Estado. La Ley 21/1976, de 14 de junio, sobre el Derecho de Asociación Política y la creación de un Registro de Asociaciones Políticas no compensa a una oposición que anhela la formación de partidos políticos e, incluso, es denunciada por Coordinación Democrática por "otorgada y antidemocrática". Los viejos e incipientes partidos políticos encuentran trabas legales para su legalización, pues se da la paradoja de que han sido aprobados por la Ley de Asociaciones, pero se encuentran prohibidos por el Código Penal.

Es el sector ciudadano, que prosigue la línea de expansión informativa $(18,84 \%)$ en relación al resto de sectores, el que desvela su malestar social y demanda derechos, en su mayoría con formatos de impacto callejero, fundamentalmente manifestacio-

12 El Parlamento Europeo en Estrasburgo aprueba por unanimidad una resolución sobre la situación española, pidiendo el restablecimiento de las libertades individuales, políticas y sindicales, así como la legalización de los partidos políticos, la amnistía para los presos políticos y el retorno de los exiliados.

13 En su discurso durante su primer viaje oficial al extranjero ante el Congreso de los Estados Unidos, el rey Juan Carlos promete implantar en España una monarquía democrática. 
nes $(76,92 \%)$. Por su parte, el sector vecinal, que cuenta con una aparición tímida en la prensa $(4,34 \%)$ y que continúa manifestándose en la calle, comprende que mediante la unión le es más fácil presionar, como lo prueba el amplio uso de asociaciones $(66,66 \%)$. A estas alturas, estos dos sectores demuestran que han perdido el miedo a expresar sus demandas públicamente a través de formatos de nivel 1, como previamente lo han hecho el sector obrero y estudiantil, observable en la tabla 2.

La dimisión de Arias Navarro y el nombramiento de Adolfo Suárez como presidente del Gobierno marcan el comportamiento de la protesta del bimestre julio-agosto, que aumenta en general unas décimas $(7,32 \%)$, acentuándose un distanciamiento entre los formatos de nivel $1(54,15 \%)$ y de nivel $2(45,82 \%)$ que se mantiene hasta el final del año (véase figura 2). La simultánea subida general de manifestaciones (40,27\%) y discursos $(38,88 \%)$ sobre el resto de formatos descubre un equilibrio entre el recelo y la confianza ante las medidas del nuevo gabinete.

Mientras se produce el diálogo entre el ministro de Relaciones Sindicales y algunos sindicatos y se constituye la Coordinadora de Organizaciones Sindicales (COS), integrada por CCOO, UGT y USO, el Boletín Oficial del Estado (BOE) publica la aplicación de la amnistía al ámbito sindical mediante el Acuerdo del 3 de agosto, pero esto no compensa al sector obrero, cuya representación periodística sigue siendo muy notoria $(52,77 \%)$ y, en medio de una sequía de convenios, opta por emplear formatos de nivel $1(60 \%)$, primordialmente, manifestaciones $(34,21 \%)$ para reivindicar asuntos propios del sector. La discordancia vecinal y cultural/artística, que continúa siendo leve, rondando el $4 \%$, se sostiene solamente mediante la vía discursiva.

El sector ciudadano consigue el dato culmen de presencia mediática $(19,67 \%)$ y maneja el porcentaje máximo de manifestaciones a lo largo del ciclo general observado $(29,09 \%)$. Entre ellas se encuentra la primera manifestación autorizada a favor de la amnistía convocada por la Coordinación Democrática de Andalucía (CDA) celebrada el 11 de julio. Cuatro días después, las cortes franquistas aprueban la modificación de los artículos del Código Penal concernientes a los delitos de reunión, manifestación, propaganda y asociación, entrando en vigor el día 21, con lo cual se legalizan los formatos de protesta, prohibidos hasta la fecha. Sin embargo, el Real DecretoLey 10/1976, de 30 de julio, sólo reconoce una amnistía parcial que incluye en exclusiva los delitos políticos y sociales que no afectan a la vida e integridad corporal. En agosto, la Coordinación Democrática expone en un documento la intención de lograr un gobierno provisional de amplio consenso democrático.

Figura 2. Evolución de los niveles de conflictividad de la protesta en la prensa de Sevilla

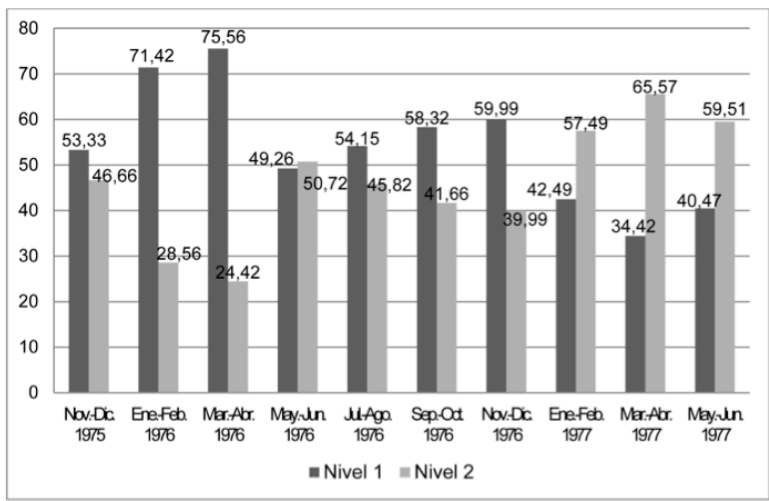

Fuente: Elaboración propia 
En un compás de espera donde el gobierno de Suárez lucha por sacar adelante el Proyecto de Ley de Reforma Política y donde la oposición política se organiza de forma independiente o asistiendo a la cumbre de la Plataforma de Organizaciones Democráticas para esbozar una síntesis de programa de ruptura democrática, el flujo de protesta general crece un punto $(8,54 \%)$ y se extiende la utilización de formatos de nivel $1(58,32 \%)$-especialmente se prolonga la cota de manifestaciones $(44,04 \%)$ respecto al resto de formatos- sobre los de nivel $2(41,66 \%)$, lo que indica que el impacto producido en la calle se intensifica en la prensa en los meses de septiembre y octubre en detrimento del formato dialéctico. Esto es perceptible en todos los sectores, excepto en el cultural/artístico, donde no se recoge ningún tipo de contestación, y en el sector ciudadano, que ve contraída su cobertura periodística a la mitad $(14,28 \%)$ del bimestre anterior con respecto a otros sectores, pero se sirve con mayor rotundidad de formatos de nivel 2: discursos $(41,66 \%)$ y asociaciones $(25 \%)$, las cuales alcanzan el valor más álgido del período íntegro de análisis $(30 \%)$.

El rechazo a la anunciada promulgación por decreto de la reforma sindical, la reclamación de amnistía laboral con la readmisión de los trabajadores despedidos y el regreso de los exiliados endurecen parcialmente la acción combativa del sector obrero con formatos de nivel $1(70 \%)$, puesto que su presencia $(35,71 \%)$ en prensa es por primera vez superada por otro sector, el estudiantil $(40,47 \%)$. La recuperación de las huelgas $(40 \%)$ se dirige a la lucha por obtener nuevos convenios colectivos. También regresan las manifestaciones estudiantiles con la vuelta a las aulas $(52,94 \%)$ y son ampliamente usadas por el sector vecinal $(75 \%)$, que restringe los discursos a la cuarta parte del bimestre anterior $(25 \%)$ en unos de los momentos en los que cuenta con una cobertura periodística más amplia $(15,68 \%)$ del tiempo completo tomado en consideración.

El índice de flujo de la protesta se perpetúa en los periódicos e incluso sube unas décimas $(8,64 \%)$ en el último bimestre del año, con un carácter más callejero al elevarse aún más la puesta en práctica de formatos de nivel 1 (59,99\%) -las huelgas $(34,11 \%)$ toman el relevo de las manifestaciones-, respecto a los de nivel $2(39,99 \%)$. La especialización de la lucha estudiantil y obrera, cuya representación mediática se sitúa en el $72,93 \%$, persiste en la calle. Son noticia principalmente las huelgas estudiantiles $(57,14 \%)$ y obreras $(41,46 \%)$ como la huelga general de 24 horas que tiene lugar el 12 de noviembre contra las medidas de ajuste laboral y económico del Gobierno no salido de las urnas y en demanda de la amnistía y las libertades democráticas.

El sector vecinal experimenta un cambio y dirige su protesta a través de un $60 \%$ de discursos para reivindicar viviendas y servicios públicos. Esta forma de expresión es exclusivamente recurrida por el sector cultural/artístico, que vuelve a la escena mediática $(7,05 \%)$, y con notoriedad por el sector ciudadano $(58,33 \%)$ que mantiene su espacio informativo (14,11\%), cuando es testigo del primer juego democrático que supone los posicionamientos del Gobierno a favor de la Ley de Reforma Política y la campaña abstencionista de la oposición política, previa reunión de la Plataforma de Organizaciones Democráticas. El respaldo ciudadano al Gobierno en las urnas el 15 de diciembre se salda en Sevilla con una participación del $77,89 \%$ y está en línea con las nuevas formas democráticas ejemplarizantes practicadas por el presidente Suárez como la del recibimiento de miembros de la comisión negociadora de la oposición que abren el diálogo entre ésta y el Gobierno.

\subsection{Dosificación de la protesta callejera en el juego democrático}

En el primer bimestre de 1977 se suscita la segunda oleada de protestas más significativa en cuanto a cobertura informativa (12,2\%), como se puede apreciar en la figura 1. Estamos ante una afluencia de menor intensidad y con un cariz diferente a 
la de enero-febrero de 1976, prolongada en marzo-abril del mismo año. Asistimos a un cambio de rumbo en la estrategia de expresión de la protesta que en la prensa se exhibe claramente mediante la publicación de formatos de nivel $2(57,49 \%)$ por encima de los de nivel 1 (42,49\%). En general, los discursos se acaban imponiendo hasta el final de la etapa estudiada sobre el resto de sectores, cuyo valor oscila entre el $45-49 \%$.

Una de las causas atribuibles es que el sector más reivindicativo hasta el momento, el obrero, recibe unos de los porcentajes inferiores de representación en prensa $(5,26 \%)$ en toda la muestra de tiempo analizada y el más exiguo en comparación con otros sectores $(20,83 \%)$, con la consecuente aminoración de las huelgas y las manifestaciones, tradicionalmente unidas al sector (véase figura 3). Igualmente, el nivel 1 de conflictividad general es el menos relevante del período total investigado $(3,52 \%)$, mientras que los discursos y las asociaciones acaparan el $76 \%$ de la contestación bimestral con un considerable incremento de las últimas (28\%), demostrando menos beligerancia en sus demandas y más confianza en un escenario en el que los sindicatos pasan a un segundo plano de protagonismos, tras la aprobación de la Ley para la Reforma Política y la inminente legalización de todos los partidos políticos.

Figura 3. Formatos de protesta por sectores en la prensa de Sevilla

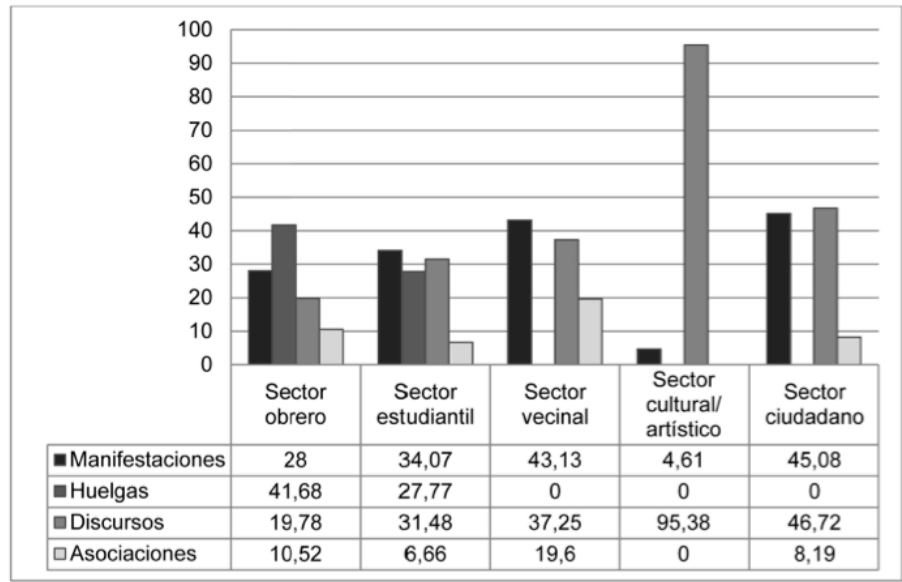

Fuente: Elaboración propia

La docilidad de la protesta coincide con medidas democratizadoras simbólicas: la supresión del TOP como símbolo de nuevos tiempos y el fin de la represión, las entrevistas de Suárez con miembros de la Comisión de los Nueve que le plantean la necesidad de una amnistía total de todos los delitos de intencionalidad política sin exclusiones y la promulgación del Decreto-Ley de 8 de febrero de 1977 sobre el derecho de asociación política, que, posteriormente, permitirá la legalización de los partidos, previo paso de apertura de la ventanilla del Ministerio de Gobernación para su inscripción.

El sector ciudadano es el que acusa más claramente este cambio de tendencia. No actúa apenas con los formatos de protesta de nivel 1 -las manifestaciones ocupan el $10 \%$ - para reaccionar por el asesinato de cinco personas en el asalto de un grupo terrorista de ultraderecha a un despacho de abogados laboralistas en la calle Atocha de Madrid y la resultante aprobación del Decreto-ley, por el que se suspenden los artículos 15 y 18 del Fuero de los Españoles, garantes de la inviolabilidad del domicilio 
y las detenciones, o porque se sigan prohibiendo conferencias y mesas redondas. Si bien, el afianzamiento de su carácter dialéctico (80\%) -los discursos logran su mejor dato del intervalo global de análisis (14,03\%)- y el retroceso de las manifestaciones en más de 20 puntos porcentuales en comparación con los dos bimestres inmediatamente anteriores tiene menores implicaciones, dado que su cobertura en prensa es mucho más limitada $(8,33 \%)$.

Con mayor asiduidad emplean formatos de nivel 1 el sector estudiantil, vecinal y cultural/artístico. Para reivindicar la democratización de la gestión educativa, la escolarización en zonas deprimidas y la renovación de estatutos universitarios, el sector estudiantil emprende una lucha con manifestaciones y huelgas -éstas adquieren su mejor apunte del ciclo íntegramente observado (24\%)- que superan el $65 \%$. Esto le permite liderar la protesta del bimestre $(45,83 \%)$, desplazando por primera vez al sector obrero al segundo lugar, y registrar la segunda cifra más alta en su propia evolución como sector $(20,37 \%)$, consiguiendo una notoriedad similar a la del bimestre enero-febrero de 1976.

La objeción del sector vecinal, que logra su mayor porcentaje en la etapa total investigada $(19,6 \%)$, se produce a través de manifestaciones $(70 \%)$, aunque las asociaciones $(30 \%)$ recuperan fuerza. En la acción discordante del sector cultural/artístico, que es la segunda más elevada del período absoluto $(30,76 \%)$ y la tercera con respecto a otros sectores del bimestre $(16,66 \%)$, entran en juego las manifestaciones $(5 \%)$ como uso excepcional, teniendo en cuenta su proclividad a operar con discursos (véase figura 3), los cuales igualan el dato más destacado como en la oleada de enero-febrero de 1976.

Conforme se divisa que el país se dirige firmemente hacia la democracia en los meses de marzo y abril, se hacen más innegables dos características de la protesta en la prensa: la bajada del flujo contestatario, que decrece a la mitad del total del bimestre anterior $(6,2 \%)$, y la acentuación de la dialéctica y del asociacionismo en el repertorio, donde la recurrencia a formatos de nivel $2(65,57 \%)$ aventaja notoriamente a la de nivel $1(34,42 \%)$. Las huelgas (2,93\%) asumen uno de sus mínimos desde el inicio del estudio. El sector ciudadano, que se sitúa en tercera posición en aparición mediática $(18,03 \%)$ con diez puntos más sobre el bimestre anterior, es el máximo exponente de este comportamiento. En un $90 \%$ se expresa con formatos discursivos y asociativos $(27,27 \%)$, los cuales avanzan en detrimento de los primeros $(63,63 \%)$ y alcanzan por segunda vez la cima del análisis global $(30 \%)$.

A ello puede contribuir el clima que genera la promulgación de varios reales-decretos $^{14}$ que avanzan en la celebración de las elecciones generales, la derogación del artículo 2 de la Ley de Prensa e Imprenta de 1966 y la desaparición de la Secretaría General del Movimiento. Estas medidas, sin embargo, resultan insuficientes para la oposición política que expone al Gobierno que, para que exista democracia, se necesita cumplir dos grandes leyes de reconciliación nacional: la amnistía para todos sin exclusiones y la legalización de todas las asociaciones políticas y sindicales que respalden la convivencia pacífica. La primera de ellas no es aceptada por Suárez, quien sólo concede un indulto por el que 74 presos vascos salen de la cárcel, a través de la aprobación del Real Decreto-ley388/1977, de 14 de marzo,

14 Real Decreto-ley 20/1977, de 18 de marzo, sobre Normas Electorales. Real Decreto-ley 24/1977, de 1 de abril, sobre libertad de expresión. Real Decreto-ley 23/1977, de 1 de abril, sobre reestructuración de los órganos dependientes del Consejo Nacional y nuevo régimen jurídico de las Asociaciones, funcionarios y patrimonio del Movimiento. 
sobre indulto general; la segunda la cumple al legalizar el Partido Comunista de España (PCE) el 9 de abril.

Los formatos de nivel 1 son recurridos por el sector estudiantil en su mayor parte $(53,83 \%)$, cuya figuración en prensa respecto a otros sectores se ve mermada a la mitad de la obtenida en el anterior bimestre (21,31\%), volviendo a ocupar el segundo lugar, y por el sector vecinal que no renuncia a las manifestaciones (25\%). Sin embargo, la proporción de asociaciones (15,38\%) en el ámbito estudiantil quintuplica el del bimestre anterior, sobrepasando los valores del inicio del curso académico; el sector vecinal apuesta más claramente por los discursos (75\%).

El protagonismo de la protesta estudiantil es relevado por el sector obrero, que recupera presencia periodística $(49,18 \%)$ sobre los otros sectores, pero continúa perdiendo impacto en la calle con una aplicación de formatos de nivel 1 que no llega al $40 \%$, mientras que los discursos $(43,33 \%)$ y las asociaciones $(16,66 \%)$ conservan sus datos con ligeras depreciaciones. La clara atenuación de las huelgas obreras $(13,33 \%)$-reciben una de las menores cifras del período $(2,02 \%)$ - en la prensa a niveles de noviembre-diciembre de 1975 se realiza en el contexto de numerosos logros sindicales.

A comienzos del bimestre marzo-abril se aprueba el Real Decreto-ley 17/1977, de 4 de marzo, sobre Relaciones de Trabajo, Huelga, Conflicto colectivo y Convenios Colectivos, y un mes más tarde, la Ley 19/1977, de 1 de abril, sobre regulación del Derecho de Asociación Sindical, supone el paso previo para la legalización de las centrales sindicales. El Gobierno procede a mediados de abril a la ratificación de los Convenios 87 (proclama el derecho de trabajadores y empresarios a constituir libremente sus organizaciones y la afiliación a las mismas) y 98 (protección de libertad sindical) de la Organización Internacional del Trabajo (OIT). Pero, nuevos problemas asoman con fuerza y hacen que se extiendan más las manifestaciones $(26,66 \%)$ : el aumento de expedientes de crisis en pequeñas y medianas empresas y el grave ascenso del paro. El 15 de abril los sindicatos CCOO y USO llaman a la acción general bajo el argumento del empeoramiento de la situación social, la carestía de la vida y las medidas económicas del Gobierno que hacen crecer la inflación de los precios sin resolver a fondo ningún problema.

La protesta se adjudica su mínima cobertura en prensa $(4,27 \%)$ a finales del intervalo total examinado. Se percibe entonces una menor diversificación en el manejo de formatos por los distintos sectores, pues ninguno se sirve de todos los formatos y los habitualmente más mediáticos (obrero, estudiantil y ciudadano) apuntan los porcentajes más bajos de la muestra analizada en contraposición al sector vecinal, que anota una eximia trascendencia informativa tras alzarse con uno de los mayores valores observados en su recorrido $(11,76 \%)$. 
Tabla 3. Evolución diacrónica de formatos de protestas según sectores sociales y bimestres en la prensa de Sevilla

\begin{tabular}{|c|c|c|c|c|c|c|}
\hline & & $\begin{array}{c}\text { Sector } \\
\text { obrero } \\
\%\end{array}$ & $\begin{array}{c}\text { Sector } \\
\text { estudiantil } \\
\%\end{array}$ & $\begin{array}{c}\text { Sector } \\
\text { vecinal } \\
\%\end{array}$ & $\begin{array}{c}\text { Sector } \\
\text { cultural/ } \\
\text { artístico } \\
\%\end{array}$ & $\begin{array}{c}\text { Sector } \\
\text { ciudadano } \\
\%\end{array}$ \\
\hline \multirow{4}{*}{$\begin{array}{l}\text { Nov.-Dic. } \\
1975\end{array}$} & Manifestaciones & 13,53 & 5,43 & 0,00 & 0,00 & 7,27 \\
\hline & Huelgas & 2,02 & 1,33 & 0,00 & 0,00 & 0,00 \\
\hline & Discursos & 9,57 & 12,94 & 0,00 & 4,83 & 7,01 \\
\hline & Asociaciones & 2,00 & 0,00 & 0,00 & 0,00 & 0,00 \\
\hline \multirow{4}{*}{$\begin{array}{l}\text { Ene.-Feb. } \\
1976\end{array}$} & Manifestaciones & 39,84 & 26,08 & 9,09 & 66,66 & 5,45 \\
\hline & Huelgas & 42,42 & 22,66 & 0,00 & 0,00 & 0,00 \\
\hline & Discursos & 12,76 & 22,35 & 15,78 & 30,64 & 8,77 \\
\hline & Asociaciones & 16,00 & 27,77 & 20,00 & 0,00 & 10,00 \\
\hline \multirow{4}{*}{$\begin{array}{l}\text { Mar.-Abr. } \\
1976\end{array}$} & Manifestaciones & 11,27 & 17,39 & 9,09 & 0,00 & 18,18 \\
\hline & Huelgas & 20,20 & 21,33 & 0,00 & 0,00 & 0,00 \\
\hline & Discursos & 7,44 & 7,05 & 5,26 & 6,45 & 14,03 \\
\hline & Asociaciones & 4,00 & 11,11 & 20,00 & 0,00 & 0,00 \\
\hline \multirow{4}{*}{$\begin{array}{l}\text { May.-Jun. } \\
1976\end{array}$} & Manifestaciones & 3,75 & 2,17 & 4,54 & 0,00 & 18,18 \\
\hline & Huelgas & 6,06 & 5,33 & 0,00 & 0,00 & 0,00 \\
\hline & Discursos & 10,63 & 9,41 & 0,00 & 3,22 & 5,26 \\
\hline & Asociaciones & 18,00 & 5,55 & 20,00 & 0,00 & 0,00 \\
\hline \multirow{4}{*}{$\begin{array}{l}\text { Jul.-Ago. } \\
1976\end{array}$} & Manifestaciones & 9,77 & 0,00 & 0,00 & 0,00 & 29,09 \\
\hline & Huelgas & 5,05 & 0,00 & 0,00 & 0,00 & 0,00 \\
\hline & Discursos & 12,76 & 3,52 & 15,78 & 4,83 & 12,28 \\
\hline & Asociaciones & 6,00 & 5,55 & 0,00 & 0,00 & 10,00 \\
\hline \multirow{4}{*}{$\begin{array}{l}\text { Sep.-Oct. } \\
1976\end{array}$} & Manifestaciones & 6,76 & 19,56 & 27,27 & 0,00 & 7,27 \\
\hline & Huelgas & 6,06 & 0,00 & 0,00 & 0,00 & 0,00 \\
\hline & Discursos & 5,31 & 12,94 & 10,52 & 0,00 & 8,77 \\
\hline & Asociaciones & 8,00 & 27,77 & 0,00 & 0,00 & 30,00 \\
\hline \multirow{4}{*}{$\begin{array}{l}\text { Nov.-Dic. } \\
1976\end{array}$} & Manifestaciones & 7,51 & 6,52 & 9,09 & 0,00 & 7,27 \\
\hline & Huelgas & 8,58 & 16,00 & 0,00 & 0,00 & 0,00 \\
\hline & Discursos & 8,51 & 3,52 & 15,78 & 9,67 & 12,28 \\
\hline & Asociaciones & 12,00 & 0,00 & 0,00 & 0,00 & 10,00 \\
\hline \multirow{4}{*}{$\begin{array}{l}\text { Ene.-Feb. } \\
1977\end{array}$} & Manifestaciones & 1,50 & 19,56 & 31,81 & 33,33 & 1,81 \\
\hline & Huelgas & 2,02 & 24,00 & 0,00 & 0,00 & 0,00 \\
\hline & Discursos & 12,76 & 20,00 & 0,00 & 30,64 & 14,03 \\
\hline & Asociaciones & 14,00 & 11,11 & 30,00 & 0,00 & 10,00 \\
\hline \multirow{4}{*}{$\begin{array}{l}\text { Mar.-Abr. } \\
1977\end{array}$} & Manifestaciones & 6,01 & 3,26 & 4,54 & 0,00 & 1,81 \\
\hline & Huelgas & 2,02 & 5,33 & 0,00 & 0,00 & 0,00 \\
\hline & Discursos & 13,82 & 4,70 & 15,78 & 4,83 & 12,28 \\
\hline & Asociaciones & 10,00 & 11,11 & 0,00 & 0,00 & 30,00 \\
\hline \multirow{4}{*}{$\begin{array}{l}\text { May.-Jun. } \\
1977\end{array}$} & Manifestaciones & 0,00 & 0,00 & 4,54 & 0,00 & 3,63 \\
\hline & Huelgas & 5,55 & 4,00 & 0,00 & 0,00 & 0,00 \\
\hline & Discursos & 6,38 & 3,52 & 21,05 & 4,83 & 5,26 \\
\hline & Asociaciones & 10,00 & 0,00 & 10,00 & 0,00 & 0,00 \\
\hline
\end{tabular}

Fuente: Elaboración propia

Aunque se estabilizan los formatos de nivel $2(59,51 \%)$ frente a los de nivel 1 $(40,47 \%)$ - sobre todo huelgas, pues las manifestaciones obtienen su peor dato en el tiempo global investigado $(0,98 \%)$ - se acortan las distancias entre los niveles de conflictividad. Este esquema se aplica con distinta gradación según los sectores. Los formatos de nivel 2 se mantienen muy activos en el sector cultural/artístico, especialmente los discursos, que suponen el $100 \%$ de la protesta del bimestre; en el sector vecinal éstos albergan el $83,32 \%$-alcanzan su principal porcentaje de todo el ciclo $(21,05 \%)$ - frente al $16,66 \%$ de manifestaciones, mientras que en el estudiantil se debate con las huelgas al $50 \%$. El sector obrero procede con formatos de ambos niveles en la misma proporción, apreciable en la tabla 4. 
Tabla 4. Evolución sincrónica de formatos de protestas según sectores sociales y bimestres en la prensa de Sevilla

\begin{tabular}{|c|c|c|c|c|c|c|}
\hline & & $\begin{array}{c}\text { Sector } \\
\text { obrero } \\
\%\end{array}$ & $\begin{array}{c}\text { Sector } \\
\text { estudiantil } \\
\%\end{array}$ & $\begin{array}{c}\text { Sector } \\
\text { vecinal } \\
\%\end{array}$ & $\begin{array}{c}\text { Sector } \\
\text { cultural/ } \\
\text { artístico } \\
\%\end{array}$ & $\begin{array}{c}\text { Sector } \\
\text { ciudadano } \\
\%\end{array}$ \\
\hline \multirow{4}{*}{$\begin{array}{l}\text { Nov.-Dic. } \\
1975\end{array}$} & Manifestaciones & 56,25 & 29,41 & 0,00 & 0,00 & 50,00 \\
\hline & Huelgas & 12,50 & 5,88 & 0,00 & 0,00 & 0,00 \\
\hline & Discursos & 28,12 & 64,70 & 0,00 & 100,00 & 50,00 \\
\hline & Asociaciones & 3,12 & 0,00 & 0,00 & 0,00 & 0,00 \\
\hline \multirow{4}{*}{$\begin{array}{l}\text { Ene.-Feb. } \\
1976\end{array}$} & Manifestaciones & 33,75 & 36,92 & 28,57 & 9,52 & 33,33 \\
\hline & Huelgas & 53,50 & 26,15 & 0,00 & 0,00 & 0,00 \\
\hline & Discursos & 7,64 & 29,23 & 42,85 & 90,47 & 55,55 \\
\hline & Asociaciones & 5,09 & 7,69 & 28,57 & 0,00 & 11,11 \\
\hline \multirow{4}{*}{$\begin{array}{l}\text { Mar.-Abr. } \\
1976\end{array}$} & Manifestaciones & 23,43 & 40,00 & 40,00 & 0,00 & 55,55 \\
\hline & Huelgas & 62,5 & 40,00 & 0,00 & 0,00 & 0,00 \\
\hline & Discursos & 10,93 & 15,00 & 20,00 & 100,00 & 44,44 \\
\hline & Asociaciones & 3,12 & 5,00 & 40,00 & 0,00 & 0,00 \\
\hline \multirow{4}{*}{$\begin{array}{l}\text { May.-Jun. } \\
1976\end{array}$} & Manifestaciones & 13,88 & 13,33 & 33,33 & 0,00 & 76,92 \\
\hline & Huelgas & 33,33 & 26,66 & 0,00 & 0,00 & 0,00 \\
\hline & Discursos & 27,77 & 53,33 & 0,00 & 100,00 & 23,07 \\
\hline & Asociaciones & 25,00 & 6,66 & 66,66 & 0,00 & 0,00 \\
\hline \multirow{4}{*}{$\begin{array}{l}\text { Jul.-Ago. } \\
1976\end{array}$} & Manifestaciones & 34,21 & 0,00 & 0,00 & 0,00 & 66,66 \\
\hline & Huelgas & 26,31 & 0,00 & 0,00 & 0,00 & 0,00 \\
\hline & Discursos & 31,57 & 75,00 & 100,00 & 100,00 & 29,16 \\
\hline & Asociaciones & 7,89 & 25,00 & 0,00 & 0,00 & 4,16 \\
\hline \multirow{4}{*}{$\begin{array}{l}\text { Sep.-Oct. } \\
1976\end{array}$} & Manifestaciones & 30,00 & 52,94 & 75,00 & 0,00 & 33,33 \\
\hline & Huelgas & 40,00 & 0,00 & 0,00 & 0,00 & 0,00 \\
\hline & Discursos & 16,66 & 32,35 & 25,00 & 0,00 & 41,66 \\
\hline & Asociaciones & 13,33 & 14,70 & 0,00 & 0,00 & 25,00 \\
\hline \multirow{4}{*}{$\begin{array}{l}\text { Nov.-Dic. } \\
1976\end{array}$} & Manifestaciones & 24,39 & 28,57 & 40,00 & 0,00 & 33,33 \\
\hline & Huelgas & 41,46 & 57,14 & 0,00 & 0,00 & 0,00 \\
\hline & Discursos & 19,51 & 14,28 & 60,00 & 100,00 & 58,33 \\
\hline & Asociaciones & 14,63 & 0,00 & 0,00 & 0,00 & 8,33 \\
\hline \multirow{4}{*}{$\begin{array}{l}\text { Ene.-Feb. } \\
1977\end{array}$} & Manifestaciones & 8,00 & 32,72 & 70,00 & 5,00 & 10,00 \\
\hline & Huelgas & 16,00 & 32,72 & 0,00 & 0,00 & 0,00 \\
\hline & Discursos & 48,00 & 30,90 & 0,00 & 95,00 & 80,00 \\
\hline & Asociaciones & 28,00 & 3,63 & 30,00 & 0,00 & 10,00 \\
\hline \multirow{4}{*}{$\begin{array}{l}\text { Mar.-Abr. } \\
1977\end{array}$} & Manifestaciones & 26,66 & 23,07 & 25,00 & 0,00 & 9,09 \\
\hline & Huelgas & 13,33 & 30,76 & 0,00 & 0,00 & 0,00 \\
\hline & Discursos & 43,33 & 30,76 & 75,00 & 100,00 & 63,63 \\
\hline & Asociaciones & 16,66 & 15,38 & 0,00 & 0,00 & 27,27 \\
\hline \multirow{4}{*}{$\begin{array}{l}\text { May.-Jun. } \\
1977\end{array}$} & Manifestaciones & 0,00 & 0,00 & 16,66 & 0,00 & 40,00 \\
\hline & Huelgas & 50,00 & 50,00 & 0,00 & 0,00 & 0,00 \\
\hline & Discursos & 27,27 & 50,00 & 66,66 & 100,00 & 60,00 \\
\hline & Asociaciones & 22,72 & 0,00 & 16,66 & 0,00 & 0,00 \\
\hline
\end{tabular}

Fuente: Elaboración propia

Este último sector disminuye su presencia mediática hasta su mínimo apunte en el transcurso observado en su totalidad $(4,63 \%)$, aunque su protagonismo en la protesta del bimestre respecto a otros sectores se cifra en un $52,38 \%$. Las huelgas que ocupan el $50 \%$ de la contestación giran sobre el grave desempleo extendido en Andalucía y la paradójica prohibición de actos sindicales para el 1 de Mayo cuando acaban de legalizarse las centrales sindicales y está a punto de desaparecer la sindicación obligatoria al Vertical mediante el Real Decreto-Ley de 12 de junio.

Los acontecimientos se precipitan en el mes de mayo: Suárez hace pública su decisión de presentarse a las elecciones liderando la recién constituida coalición UCD 
(Unión de Centro Democrático), don Juan de Borbón renuncia a sus derechos históricos a la Corona, el Rey nombra a cuarenta y un senadores, como establece la Ley para la Reforma Política, y los partidos políticos dan a conocer a sus líderes y programas ante las inminentes elecciones generales del 15 de junio. La protesta ciudadana que vuelve a decaer en la prensa $(11,90 \%)$ en el bimestre, obteniendo la más baja en el tiempo $(4,09 \%)$, se dirime entre los discursos $(60 \%)$ y las manifestaciones $(40 \%)$ para expresar la expectativa de amnistía total que el Gobierno no ha satisfecho y que no se consigue hasta la promulgación de la Ley 46/1977 de 15 de octubre.

\section{Conclusiones}

El concepto mediático añade a las posturas históricas y sociológicas sobre la desmovilización y el resurgimiento ciudadano la interpretación de que existe un resurgimiento ciudadano mediático, en tanto que la sociedad civil es sujeto activo de textos sobre la protesta y protagoniza acciones de presión y consecución de objetivos en la prensa. Se observan tres características que definen la naturaleza de la protesta mediática: 1) la canalización de la protesta hacia el diálogo y el asociacionismo, pese a que los formatos de nivel 1 de conflictividad son los más interesantes desde el punto de vista del valor/noticia; 2) la especialización sectorial como representación social, donde los sectores obrero y estudiantil marcan el ritmo de presiones más que ningún otro, y 3 ) la normalización de la imagen de la protesta en unas condiciones donde los límites de la legalidad/ilegalidad y legitimidad/ilegitimidad están difusos, lo que lleva aparejada la institucionalización del conflicto y la legalización del repertorio contestatario que acaba integrándose en el juego democrático para defensa de intereses concretos como el caso del sector obrero al final del período estudiado.

La protesta mediática presenta, además, una modulación del empleo del repertorio por niveles de conflictividad, siguiendo un esquema comunicativo constante de estímulo-respuesta entre la acción política y ciudadana, como refleja la figura 4, que se manifiesta con distinto cariz en tres períodos: a) desde la prudencia después de la muerte de Franco a marzo-abril de 1976 cuando se exterioriza el auge de desaprobación más elevado con formatos de nivel 1 como incitación a los políticos desde la ciudadanía; b) desde mayo-junio a noviembre-diciembre de 1976 cuando tiene lugar un aumento de formatos de nivel 1 como motor de presión y de nivel 2 como respuesta dialéctica a los estímulos que suponen la puesta en escena de una oposición política unificada, las primeras medidas reformadoras del gobierno de Suárez y la legalización del repertorio, y c) durante los primeros seis meses de 1977 cuando se produce una clara imposición del diálogo y del asociacionismo y se dosifica la protesta callejera como vehículo negociador.

Figura 4. Esquema comunicativo de la sociedad civil y la clase política en la prensa de Sevilla durante la transición democrática

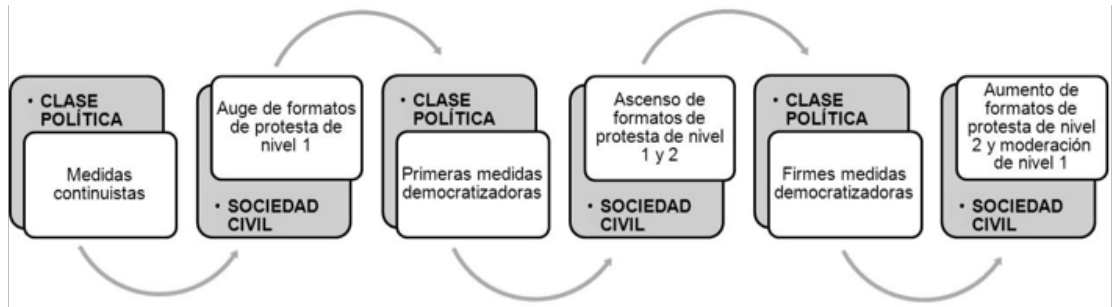

Fuente: Elaboración propia 
Este resurgimiento ciudadano mediático, que protagonizan unos sectores sociales concretos, alcanza a la sociedad en su conjunto, estableciéndose dos acciones: el efecto de contestación recompensada y la acción metonímica. Según el esquema comunicativo observado en la prensa, la protesta mediática recompensada con medidas políticas satisfactorias descubre que la sociedad civil reconduce el malestar social general y es diseñadora activa de su propio destino en un logro común, lo que, sin duda, ayuda a la clase política a no contar con ningún obstáculo a la hora de dirigir el cambio. Asimismo, en el imaginario común plasmado por las teorías históricas y sociológicas del resurgimiento ciudadano, se toma la lucha democrática como ejercicio de todos los ciudadanos españoles. No obstante, el estudio de la protesta mediática indica que, por una acción metonímica, el conjunto de la sociedad española se reconoce solidariamente en la sociedad civil que aparece en la prensa, asume su acción reprobatoria como propia y, por ende, hace extensibles los logros conseguidos por unos sectores concretos, idea que viene a engrosar la teoría de la desmovilización ciudadana que defiende que la participación de los españoles es más de pensamiento que de acción misma.

En síntesis, partiendo del argumento de la influencia de la protesta social en las medidas políticas democratizadoras sobre la que se sustentan los dos ejes que explican el éxito de la transición democrática, el resurgimiento y la desmovilización de la sociedad civil -el otro argumento es la existencia de una cultura democrática-, el estudio realizado sobre la acción colectiva a través del repertorio de protesta social en la prensa, situado en el contexto de los acontecimientos, nos ha permitido comprobar que la sociedad civil ejerce cierta influencia en las decisiones de la clase política dirigente y exponer, por tanto, que existe un resurgimiento ciudadano mediático. Si bien este resurgimiento mediático se toma como acción generalizada de la sociedad por efecto espejo, dando la razón a las tesis que apunta a una desmovilización real. Con todo ello, la prensa amplía su papel resocializador a la hora de configurar la actitud del conjunto de la sociedad española en la transición, lo cual supone un aporte diferenciado que complementa las visiones históricas y sociológicas sobre el proceso democrático.

\section{Referencias bibliográficas}

Aparici, R. (2010). La construcción de la realidad. En R. Aparici (Coord.), La construcción social en los medios de comunicación. Madrid: Universidad Nacional de Educación a Distancia.

Aróstegui, J. (2000). La Transición (1975-1982). Madrid: Acento.

Attili Card Amone, A. (2004). Ciudadanía, sociedad civil y la redefinición de los espacios públicos. Revista de Estudios Políticos (Nueva Época), n 126, 131-150.

Auyero, J. (2002). Los cambios en el repertorio de la protesta social en Argentina. Desarrollo Económico, vol. 42, nº 166, 187-210.

Aya, R. (1995). La protesta como política: generalización y explicación en la sociología histórica. Política y Sociedad, $\mathrm{n}^{\circ} 18,107-113$.

Barrera, C. (1995). Sin mordaza. Veinte años de prensa en democracia. Madrid: Temas de hoy.

Buil-Merce, M. A. (2000). Democracy and constitutional consolidation. The cases of Poland and Spain. Oxford: Lincoln College, University of Oxford. Recuperado de http:// web.cenet.org.cn/upfile/42069.pdf. 
Caro Cancela, D. (2000). Crisis del Franquismo, Transición y ruptura sindical. En E. Lemus López y L. Álvarez Rey, (Coords.), Sindicatos y trabajadores en Sevilla. Una aproximación a la memoria del siglo XX (335-360). Sevilla: Universidad de Sevilla.

Carrillo-Linares, A. (2006). Movimiento estudiantil antifranquista, cultura política y transición política a la democracia. Pasado y Memoria. Revista de Historia Contemporánea, $n^{\circ} 5,149-172$.

Conversi, D. (2002). The Smooth Transition: Spain's 1978. Constitution and the Nationalities Question. National Identities, vol. 4, nº 3. DOI: 10.1080/1460894022000026105.

De Villiers, D. (1999). Spain: a model transition to democracy-lessons for South Africa. Politeia, $n^{\circ} 3$, vol. 18, 5-22.

De Zan, J. (2006). Los sujetos de la política. Ciudadanía y Sociedad Civil. Tópicos, $\mathrm{n}^{\circ}$ 14, 97-118. Recuperado de http://www.scielo.org.ar/scielo. php?script=sci_arttext\&pid=S1666-485X2006000100005\&Ing=es\&nrm=iso.

Dorado, R. y Varela, I. (1989). Estrategias políticas durante la transición. En J. F. Tezanos, R. Cotarelo y A. de Blas (Eds.), La transición democrática española (251-274). Madrid: Sistema.

Ferrés i Prats, J. (2003). Educación en medios y mecanismos de identificación. Revista de Educación, $\mathrm{n}^{\circ}$ 5, 51-59.

García San Miguel, L. (1981). Teoría de la Transición: un análisis del modelo español, 1973-1978. Madrid: Editora Nacional.

Gomis, L. (1987). El medio "media”. La función política de la prensa. Barcelona: Mitre.

González de Molina, M. y Gómez Oliver, M. (Coords.) (2000). Historia contemporánea de Andalucía. Nuevos contenidos para su estudio. Granada: Consejería de Educación y Ciencia de la Junta de Andalucía.

Habermas, J. (1998). Facticidad y validez. Sobre el Derecho y el Estado democrático de derecho en términos de teoría del discurso. Madrid: Trotta.

Hill, C. (2005). Motors of change? Elite actors and the Spanish transition to democracy (1975 -1981). (Tesis doctoral inédita de doctorado). School of Politics, University of Nottingham. Recuperado de http://etheses.nottingham.ac.uk/1068/1/431250.pdf.

Jaime-Jiménez, O. y Reinares, F. (1998). The policing of social protest in Spain: from Dictatorship to Democracy. En D. Della Porta y H. Reiter (Eds.), Protest policing in contemporary democracies (166-187). Minnesota: Minnesota University Press.

Juliá, S. y Mainer, J. C. (2000). El aprendizaje de la libertad (1973-1986). La cultura de la transición. Madrid: Alianza Editorial.

Kaldor, M. (2005). La sociedad civil global. Una respuesta a la guerra. Barcelona: Tusquets.

Köhler, H. D. (1995). El movimiento sindical en España. Transición democrática. Regionalismo. Modernización económica. Madrid: Fundamentos.

Lemus López, E. (1998). “La transición del consenso”. En E. Lemus López y L. Álvarez Rey (Coords.), Historia de Andalucía. Huelva: Universidad de Huelva.

Linz, J. J. y Stepan, A. (1996). Problems of Democratic Transition and Consolidation. Baltimore: Johns Hopkins University Press. 
Linz, J. J. (1992). La transición a la democracia en España en perspectiva comparada. En R. Cotarelo (Ed.), Transición política y consolidación democrática (431-460). España 1975-1986. Madrid: Centro de Investigaciones Sociológicas.

López Cantos, F. J. (2006). Formación de capital social en democracia. Sociedad civil y modelos comunicativos. Global Media Journal México, vol. 6, $\mathrm{n}^{\circ} 3$. Recuperado de http://gmje.mty.itesm.mx/lopez_cantos.htm.

López Pintor, R. (1982). La opinión pública española: del franquismo a la democracia. Madrid: Centro de Investigaciones Sociológicas.

López Pintor, R. y Buceta, R. (1975). Los españoles de los años 70. Una versión sociológica. Madrid: Tecnos.

Martín García, O. (2010). Crisis del franquismo, conflictividad social y cambio democrático en España. Un análisis desde las fuentes diplomáticas británicas. En E. Lemus, F. Rosas y Fernando y R. Varela (Coords.), El fin de las dictaduras ibéricas (1974-1978) (135-152). Sevilla: Centro de Estudios Andaluces.

Molinero, C. y Ysás, P. (1992). Movimientos sociales y actitudes políticas en la crisis del franquismo. Historia contemporánea, nº 8, 269-280.

Muro, D. y Alonso, G. (Eds.) (2011). Politics and Memory in Transitions to Democracy. The Spanish Model. New York: Routledge.

O'Donnel, G. y Schmitter, P. C. (1986). Transitions from Authoritarian Rule: Tentative Conclusions. Baltimore: Johns Hopkins University Press.

Palacio Atard, V. (1989). Juan Carlos I y el advenimiento de la democracia. Madrid: Espasa Calpe.

Pérez Díaz, V. (1987). El retorno de la sociedad civil. Respuestas sociales a la transición política, la crisis económica y los cambios culturales de España 1975-1985. Madrid: Instituto de Estudios Económicos.

Pérez Ledesma, M. (2006). "Nuevos" y "viejos" movimientos en la transición. En C. Molinero Ruiz (Coord.), La Transición, treinta años después (117-151). Madrid: Península.

Preston, P. (1986). El triunfo de la democracia en España, 1969-1982. Barcelona: Plaza \& Janés.

Rodrigo Alsina, M. y Medina Bravo, P. (2009). Los medios de comunicación en contextos interculturales. Sociedad y Discurso, $n^{\circ} 16,21-39$.

Sastre García, C. (1997). La transición política en España: una sociedad desmovilizada. Revista Española de Investigaciones Sociológicas, $n^{\circ}$ 80, 33-68.

Saz Campos, I. (2010). La lucha por la libertad en España desde una perspectiva comparada (1962-1977). En C. Navajas Zubeldía y D. Iturriaga Barco (Coords.), Novísima: II Congreso Internacional de Historia de Nuestro Tiempo (71-80). Logroño: Universidad de La Rioja.

Schuster, F. (2005). Las protestas sociales y el estudio de la acción colectiva. En F. Naishtat, F. Schuster, G. Nardacchione y S. Pereyra (Comps.), Tomar la palabra. Estudios sobre protesta social y acción colectiva en la Argentina contemporánea (43-83). Buenos Aires: Prometeo. 
Seco Serrano, C. (1991). La transición a la democracia (1975-1982). En A. Domínguez Ortiz, (Dir.), Historia de España. El régimen de Franco y la transición a la democracia (de 1939 a hoy) (249-463). Barcelona: Planeta.

Sinova, J. (1989). La censura de prensa durante el franquismo (1936-1951). Madrid: Espasa Calpe.

Soto, A. (1998). La transición a la democracia. España 1975-1982. Madrid: Alianza.

Tarrow, S. (2004). Poder en movimiento. Los movimientos sociales, la acción colectiva y la política. Madrid: Alianza Editorial.

Tilly, C. (1978). From Mobilization to Revolution. Reading: Addison-Wesley.

Tuchman, G. (1972). La objetividad como ritual estratégico: un análisis de las nociones de objetividad de los periodistas. American Journal of Sociology, vol. 7, n 4, 660-679.

Tusell, J. (1989). La España de Franco. El poder, la oposición y la política exterior durante el franquismo. Madrid: Historia 16.

Tusell, J. y Soto, A. (eds.) (1996). Historia de la transición (1975-1986). Madrid: Alianza.

Valenzuela, S. (1990). Democratic consolidation in post-transitional settings: notion, process, and facilitating conditions. Working Paper, $n^{\circ} 150$. Recuperado de http://kellogg. nd.edu/publications/workingpapers/WPS/150.pdf.

Van Dijk, T. (2005). Ideología y análisis del discurso. Utopía y Praxis Latinoamericana, Revista Internacional de Filosofía Iberoamericana y Teoría Social, n² 29, 9-36.

Vilar, S. (1976). La oposición a la dictadura. Protagonistas de la España democrática. Barcelona: Ayma.

Waisman, C. H. y REIN, R. (eds.) (2011). Spanish and Latin American Transitions to Democracy. Brighton: Sussex Academic Press.

Weingast, B. R. (2000). Constructing Self-Enforcing Democracy in Spain. Recuperado de http://papers.ssrn.com/sol3/papers.cfm?abstract_id=1153464. 